\title{
REGULATING INDEPENDENT FINANCIAL ADVISERS: CURRENT TRENDS AND REFORM PROPOSALS, BETWEEN THE EU AND THE NATIONAL LEVEL ${ }^{*}$
}

\author{
di \\ Riccardo De Caria \\ (Università di Torino)
}

22 febbraio 2012

Sommario: 1. Introduction. 2. What exactly do we mean by independent financial advisers? The problem with definition. 3. Benefits (and some limits) of independent financial advice. 4. Regulation of financial advice in the EU, the UK and Italy: the essentials. 5. Is financial advice adequately regulated? An assessment of the state of the art. 6. Reform proposals: the ongoing MiFID review, other hypotheses of overhaul, and a bigger role for competition law.

\section{Introduction}

The purpose of this work is to inquire into the rules governing the activity of independent financial advisers. The reason for concentrating on this topic is that, as their very name makes it clear, they are by definition immune from the conflicts of interests that typically affect other financial institutions providing financial advice. This seems to be a particularly valuable asset to which financial regulators should attach proper consideration, particularly when trying to work out regulatory solutions aimed at preventing the occurrence of other crises, as seems to

\footnotetext{
* Articolo sottoposto a referaggio. For the great help they offered me for this article, with their precious comments, suggestions and clarifications, I would like to thank very much Professor Julia Black (LSE), Jacqueline Thornton (AIFA), Margherita Sperotti (NAFOP), Giovanni Cuniberti (G2C and Università di Torino), and my former classmate at LSE, the lawyer Markus Pinggera (Binder Grösswang).
} 
be the underlying rationale of all the recent efforts to overhaul the framework for financial regulation, both at global and national level.

The structure of the work - whose focus is confined to the EU system and particularly to two countries taken as a case-study, the UK and Italy - is the following: first of all, we will clarify what we mean precisely by independent financial advisers: the name clearly gives an idea of what we are referring to, but it is obviously very important to identify from the outset, precisely what the law means by such notion. In particular, we will consider the issue of remuneration of independent financial advisers, which is crucial for defining their notion ( $\S$ 2).

After that, we will go into more details on why independent financial advisers seem to be particularly promising in working around the conflicts of interests typical of traditional investment firms, and why in terms of policy it would seem wise to encourage the development of such an alternative channel for financial investments, also as a possible alternative to heavier regulation of the traditional channels (§3).

Next, we will consider the key features of independent financial advisers regulation, starting from the EU Directive on markets in financial instruments (MiFID) ${ }^{1}$ and then analysing two very different countries, the UK and Italy: we will use them as case-studies because, from a historical point of view, they are at the respective ends of the spectrum, the former having a 20-years experience in the regulation of the subject, while the latter only recently having started to adopt its first laws on it (§ 4).

We will then move to the assessment of such regulatory architecture, trying to understand if it adequately protects and promotes an effective competition to incumbent financial institutions from independent financial advisers, if the reform trend manifested in the UK in the recent years has gone in the right direction, and if the Italian newly-approved regulation is a fertile environment for the growth of this new profession, all this against the background of the EU framework (§ 5).

Finally, we will go a step further, trying to understand if the current reform proposals at the EU level are to be welcomed, to imagine what other improvements could be made to the existing regime, and to appraise to what extent there is a need for competition law to complement sector-specific regulation, if we want to encourage the development of a lively industry of independent financial advice (§ 6).

\footnotetext{
1 Directive 2004/39/EC of the European Parliament and of the Council of 21 April 2004 on markets in financial instruments amending Council Directives 85/611/EEC and 93/6/EEC and Directive 2000/12/EC of the European Parliament and of the Council and repealing Council Directive 93/22/EEC, OJ 2004 No. L145/1.
} 


\section{What exactly do we mean by independent financial advisers? The problem with definition}

\subsection{EU law}

Normally, the layman would probably understand the notion of independent financial adviser as a professional adviser on financial investments who is not connected to and does not act on behalf of other financial institutions, but is typically self-employed, or anyway should have no links with others than the client. An essential feature would also seem to be the remuneration, i.e. one would think that, in order to be truly 'independent', independent financial advisers should only receive remuneration from the client, and not from the providers of the financial products they advise their clients to buy. To what extent does the law reflect this man-in-thestreet intuition? Let us now consider this question, while in $\S 5$ we will ask if the legal definitions are satisfactory, if they describe a financial adviser that we can genuinely deem independent.

The answer has to be found in the law of the single EU Member States, because there is currently no uniform definition in the EU legislation. Indeed MiFID only defines what an 'investment firm' is, namely «any legal person whose regular occupation or business is the provision of one or more investment services to third parties and/or the performance of one or more investment activities on a professional basis» ${ }^{2}$, and adds that 'investment services' include «investment advice» ${ }^{3}$.

On its turn, 'investment advice' is defined as «the provision of personal recommendations to a client, either upon its request or at the initiative of the investment firm, in respect of one or more transactions relating to financial instruments» ${ }^{4}$. The key elements are therefore that the recommendation must be personalised, and that it must concern a specific investment product (not a generic asset class) ${ }^{5}$.

MiFID's Level 2 Implementing Directive ${ }^{6}$ further clarifies, in Article 52, that «a personal recommendation is a recommendation that is made to a person in his capacity as an investor or potential investor, or in his capacity as an agent for an investor or potential investor. That recommendation must be presented as suitable for that person, or must be based on a

2 Article 4(1)(1).

3 Article 4(1)(2) and Annex I, Section A, (5).

4 Article 4(1)(4).

5 N. Moloney, How to Protect Investors. Lessons from the EC and the UK (Cambridge, 2010), pp. 203-4.

6 Commission Directive 2006/73/EC of 10 August 2006 implementing Directive 2004/39/EC of the European Parliament and of the Council as regards organisational requirements and operating conditions for investment firms and defined terms for the purposes of that Directive, OJ 2006 No. L241/26. 
consideration of the circumstances of that person, and must constitute a recommendation to take one of the following sets of steps: (a) to buy, sell, subscribe for, exchange, redeem, hold or underwrite a particular financial instrument; (b) to exercise or not to exercise any right conferred by a particular financial instrument to buy, sell, subscribe for, exchange, or redeem a financial instrument. A recommendation is not a personal recommendation if it is issued exclusively through distribution channels or to the public».

Thus what we derive from these two Directives is that, under EU law, independence is not an essential feature of financial advice: it can be provided by independent advisers as well as by 'tied agents' ${ }^{7}$. But what the EU law does not do is to define what advice can be considered to be provided "independently". Therefore we need to turn to the national laws: as anticipated, we will consider the UK and Italy.

\subsection{UK law}

In the UK, the notion of Independent Financial Adviser (IFA) ${ }^{8}$ dates back to 1987, when the Securities and Investments Board (SIB) - the former City regulator, established by the Financial Services Act 1986 - «ruled that there should be only two types of advisers: independent ones, who could advise across the range of products, and tied agent/company representatives who were restricted to advising on the products of just one company. This division became known as 'polarisation'» 9 .

With polarisation, which came into effect in 1988, IFAs were therefore one of the two categories of professionals providing for financial advice, and their distinguishing feature was that they «acted as investors' agents and, in compliance with a 'best interests' requirement, advised on the market range of products» ${ }^{10}$. The SIB had also coupled polarisation with disclosure requirements, according to which the advisers of both categories had to «disclose their status to the consumer at the outset of the advice process. This was so that the consumer

7 Article 4(1)(25) MiFID.

8 We will therefore use the acronym IFA only to refer to the specific notion of Independent Financial Adviser under UK law, using the extended form, in lower case, 'independent financial advisers', to refer generically to financial advisers that are qualified by being independent.

9 P. Smee, 'To polarise or not to polarise', (2002) 10 Journal of Financial Regulation and Compliance : 135-40, 135. As explained by I. MacNeil, An Introduction to the Law on Financial Investment (Oxford and Portland, Oregon, 2005), p. 168: «Prior to the Financial Services Act 1986, the provision of investment advice was not regulated in terms of the status of the adviser or the substance of the advice. It was therefore primarily controlled by the common law of agency». See also J. Black, Rules and Regulators (Oxford, 1997), p. 47: «investment advisers [...] were not covered by the [Prevention of Fraud (Investment)] Act [1958] and were unregulated». 10 Moloney, How to Protect Investors, p. 268. More deeply on polarisation, see also Black, Rules and Regulators, pp. 148-55. 
could understand the nature of the advice they were being given and the range of products that the adviser was able to sell» ${ }^{11}$.

However, polarisation was criticised by the Office of Fair Trade for its alleged anticompetitive effects ${ }^{12}$. Pursuant to such critiques, and as a result of the fact that, contrary to the expectations, the majority of financial advisers had chosen to be tied $^{13}$, an overhaul took place $^{14}$. The new financial regulator that, according to the Financial Services and Market Act 2000 (FSMA), replaced the Financial Services Authority (FSA), decided to go down the opposite road, and in 2004 it enacted the so called 'depolarisation' reform (fully effective since June 2005). With the new rules, financial advisers could choose among three options: «offer advice from the whole of the market, from a limited number of providers, or [from] a single provider» ${ }^{15}$.

The latter choice corresponded to what since 1988 had been the tied agents; the second category became known as multi-tied agents ${ }^{16}$; but what matters more for our purposes is the first one, which was on its turn divided into two different subcategories: «untied and commission-based 'whole of the market' firms» and «independent advisers advising on 'whole of the market' products and offering a 'fee option'» ${ }^{17}$. With the 2004 reform, then, the notion of IFA changed, and more precisely it became narrower: «From 1 June 2005 firms giving investment advice and offering products from the whole market c[ould] call themselves 'independent' only if they offer[ed] [...] the option of paying by fee» ${ }^{18}$.

This clearly meant that IFAs could continue to receive compensation by way of commissions, but they had to offer also the fee-based option. As we shall see, the topic of remuneration is

11 Smee, To polarise or not to polarise, p. 136. To be sure, «linked to the rules on polarisation was [also] an agreement between members of LAUTRO on the maximum commissions to be paid to IFAs. The object was to avoid commission bias in the advice given to potential investors. The agreement did not apply to tied advisers» (Director General of Fair Trading, The Rules on the Polarisation of Investment Advice, August 1999, p. 15). As explained by Black, Rules and Regulators, p. 49, such agreement was declared to be anti-competitive by the OFT in March 1988, and subsequently abandoned.

12 Director General of Fair Trading, The Rules on the Polarisation of Investment Advice (August 1999), see especially paragraphs 7.8 to 7.20: in particular, polarisation was found to prevent the emergence of some potentially useful innovations in retail distribution (as mentioned in note 11, more than ten years earlier the OFT had already ruled out the maximum commissions agreement established by LAUTRO).

13 Black, Rules and Regulators, p. 150.

14 As made clear in the several FSA consultation papers that paved the way to the reform finally brought about with the Policy Statement 04/27 (CP 80 of January 2001, CP 121 of January 2002, CP 166 of January 2003, CP 04/3), the goal was also pursued to offer consumers «a wider range of advice options, greater variety and higher quality of financial products and [...] a greater degree of competition between direct-selling providers» (in the words of MacNeil, An Introduction to the Law on Financial Investment, p. 169).

15 FSA, Fsa rules herald new era of financial advice (FSA/PN/103/2004, 29/11/2004). See COB 5.1.6A.R(1).

16 This option was actually prevalent before 1986, but the SIB removed it «in the name of investor protection» (G. McMeel, J. Virgo, Financial advice and financial products. Law and Liability, Oxford, 2001, p. 315): indeed «the greatest confusion was caused by this 'middle ground'» (Black, Rules and Regulators, p. 142).

17 Moloney, How to Protect Investors, p. 268.

18 FSA, FSA guide to financial advice (August 2005), p. 13. 
critical to the viability of the independent financial advisers' profession; as for the moment, it is just worth underlining that, under the 2004 reform, fee remuneration was just one option for IFAs, but they could still be paid on a commission basis (in fact, it is «at present, the most common method by which independent adviser firms are paid» ${ }^{19}$ ). In concreto, this implied that, if the customer chose to pay his IFA by fee, the IFA had to pass him on the commissions he might receive from the provider of the product ${ }^{20}$.

Depolarisation was initially accompanied by some disclosure requirements, «in the form of a 'Menu', which required firms to disclose the maximum commission they received on products as well as the market average for a range of products, and in the form of an Initial Disclosure Document (IDD) on the type of service provided»; however, «these requirements were reformed and lightened post-MiFID» ${ }^{21}$, and in particular the so called 'Menu' and the related maximum commission requirement were set aside ${ }^{22}$.

In any case, very recently the regulatory picture has changed again: within the framework of the Retail Distribution Review ${ }^{23}$, the FSA removed the previous requirements, and replaced them with new ones, that will come into force on 31 December $2012^{24}$. Starting from that date, financial advisers will be able to call themselves independent (as opposed to the new category of restricted) only if the personal recommendations they offer their clients are: «(a) based on a comprehensive and fair analysis of the relevant market; and (b) unbiased and unrestricted» ${ }^{25}$.

19 FSA, Retail Distribution Review. Including feedback on DP07/1 and the Interim Report (FS 08/6, November 2008), p. 32. As a consequence, «very few adviser firms receive a significant proportion of their income» from fees (p. 37).

20 See COB 4.3.6.R(2).

21 Moloney, How to Protect Investors, p. 268.

22 By the 'Disclosure Documents (Amendment) Instrument 2008' (FSA 2008/35); these rules had been introduced by the 'Depolarisation Instrument 2004' (FSA 2004/89) (and reformulated by the 'Conduct of Business Sourcebook (MiFID, Article 4 and Other Amendments) Instrument 2007' (FSA 2007/44). See § 4.2 for the most recent rules on disclosure, scheduled to come into force at the end of 2012.

23 The ongoing process of rethinking of the regulation of investment products retail distribution, set off by former FSA Chief Executive John Tiner in June 2006, and then effectively started with FSA DP 07/1 (June 2007).

24 The overhaul was brought about by the Retail Distribution Review (Adviser Charging) Instrument 2010 (FSA 2010/12).

25 COBS 6.2A.3R, to which also the new Glossary definition makes reference (COBS 6.2A.15G further explains that, in order to meet this rule, «a firm should ensure that it is not bound by any form of agreement with a retail investment product provider that restricts the personal recommendation the firm can provide or imposes any obligation that may limit the firm's ability to provide a personal recommendation which is unbiased and unrestricted»). As underlined in FSA, Retail Distribution Review. Including feedback on DP07/1 and the Interim Report (FS 08/6, November 2008) p. 33, this marks a shift towards a «more principles-based approach». Generally on principles-based regulation, see J. Black, M. Hopper and C. Band, 'Making a Success of PrinciplesBased Regulation', (2007) 1 (3) Law and Financial Markets Review : 191-206; J. Black, 'Forms and Paradoxes of Principles Based Regulation', (2008) 3 (4) Capital Markets Law Journal : 425-457; J. Black, 'The Rise, Fall and Fate of Principles Based Regulation', LSE Law, Society and Economy Working Papers 17/2010, available at http://www.lse.ac.uk/collections/law/wps/WPS2010-17_Black.pdf. 
The former principle means that IFAs need «to be able to review the whole market» ${ }^{26}$, something very similarly to the previous 'whole of the market' requirement ${ }^{27}$ (but until now, this requirement only related to packaged products ${ }^{28}$, while since the end of 2012 it will have a wider scope ${ }^{29}$ ). As for the latter, advice cannot be considered unbiased if advisers «receive commissions set by product providers in return for recommending their products» ${ }^{30}$, or unrestricted if it only encompasses products «from a restricted range of companies or just one, rather than from the whole market» ${ }^{31}$.

What needs to be pointed out is that the new regulatory regime forbids all financial advisers, namely both independent and restricted, to receive commissions from product providers: instead, all advisers are requested to autonomously set their 'adviser charge', ideally agreeing it with their clients, but in any case without any involvement from product providers. Indeed, as explained by the FSA, «this change w[ill] be most meaningful for independent advisers providing a way to demonstrate their independence from any product provider» ${ }^{32}$, but it also applies to restricted advisers.

This means that, at the end of the day, with the new rules, the key feature that will distinguish IFAs will be the fact that they shall advise on the whole range of available products within a certain relevant market, remuneration not being any more a distinguishing feature; also, as under EU law, in the UK too independence keeps not being a necessary feature of 'financial advice $^{33}$.

\subsection{Italian law}

Let us now compare the final stage of the UK normative evolution just outlined, with the definition of independent financial advisers under Italian law. As was mentioned, regulation of this profession is very recent and not yet comprehensive. But the key points are already well-defined, and among these there is the definitional issue.

26 FSA, Retail Distribution Review. Including feedback on DP07/1 and the Interim Report (FS 08/6, November 2008), p. 42.

27 See FSA, Notification and justification for amending certain requirements relating to the market for packaged products under Article 4 of Directive 2006/73/EC ("Level 2 Directive") implementing Directive 2004/39/EC ("Level 1 Directive") (March 2010), p. 4.

28 As results from COBS 6.2.15R: «(1) A firm must not hold itself out to a client as acting independently unless it intends to: (a) provide personal recommendations to that client on packaged products from the whole market [...]». As we shall see in § 4.2, COBS 6.2 will be deleted in its entirety, effective 31 December 2012.

29 See $\S 4.2$.

30 FSA, Distribution of retail investments. Delivering the RDR - feedback to CP09/18 and final rules (PS 10/6, March 2010), p. 4.

31 Ibid., p. 15.

32 FSA, Retail Distribution Review. Including feedback on DP07/1 and the Interim Report (FS 08/6, November 2008), p. 31.

33 See the Handbook Glossary definition of "financial adviser". 
First of all, Article 1, § 5-septies of Legislative Decree 24 February 1998, No. $58^{34}$ defines "investment consultancy" (i.e.: advice) as «the provision of customised recommendations to a customer upon request or as an initiative by the service provider, regarding one or more transaction on an identified financial instrument» ${ }^{35}$. As in the EU and the UK, then, independence is not a necessary requirement of financial advice ${ }^{36}$.

However, it is provided that independence is an essential feature of 'consulenti finanziari' (CF) ('financial advisers'; literally: consultants) and 'società di consulenza finanziaria' (SCF) ('financial advice companies'). These are the two Italian categories of independent financial advisers, respectively referring to natural (Art. 18-bis of Legislative Decree 24 February 1998, No. $58^{37}$ ) and legal persons (Art. 18-ter $\left.{ }^{38}\right)^{39}$. Yet interestingly enough, Italian law does not use the word 'independent' to refer to them, so in neither case their official designation includes this qualification.

This has been creating some confusion in the general public, which tends not to be particularly aware of the difference between them and the Italian equivalent of tied or restricted advisers, i.e. 'promotori finanziari' ('financial promoters') ${ }^{40}$. That is why, in the common parlance, CF and SCF tend to add the qualification of 'indipendente' ('independent') to their job, identifying themselves as independent CF and SCF.

In any case, both Art. 18-bis and 18-ter stipulate that independence is one of the requirements that CF and SCF must necessarily meet ${ }^{41}$. What is meant by independence is specified by a Decree of the Minister of the Treasury ${ }^{42}$. Essentially, it means two things: CF and SCF shall

34 Added by Article 1 of Legislative Decree 17 September 2007, No. 164.

35 The translation is the unofficial one provided by the Italian financial regulator, CONSOB, on its website, http://www.consob.it/. In line with Art. 52 of MiFID's Level 2 Implementing Directive, Art. 1, § 5-septies also adds that «the recommendation shall be customised when it is presented as suitable for the customer or is based on consideration of the customer's characteristics. A recommendation shall not be customised if disclosed to the public through distribution channels».

36 For a partially disagreeing view, see L. Zitiello, 'La consulenza in materia di investimenti', in L. Zitiello, La nuova disciplina dei mercati, servizi e strumenti finanziari (Torino, 2007), p. 452.

37 Added by Article 3, para. 3 of Legislative Decree 17 September 2007, No. 164.

38 Added by Article 2 of Law 18 June 2009, No. 69.

39 As we saw, this distinction is unknown in the UK.

40 Inability of the general public to appreciate the difference between independent and non-independent advice seems to be a common feature with the UK, where the need to counteract this misunderstanding has been one of the drivers of the RDR: see FSA, Notification to the European Commission, supra note 27, pp. 5-6.

41 There are also other minor requisites in order to be admitted to the register for CF and SCF, but they are not particularly relevant to our purposes. We will just recall that both CF and SCF are not allowed to «hold money or financial products belonging to their clients» (Art. 18-bis and Art. 18-ter), a point we will explore more broadly in $\S \S 4.3$ and 5 .

42 For CF, it is Decree 24 December 2008, No 206 (Art. 5); for SCF, currently only a draft, published on 15 March 2011, is available (see

http://www.dt.mef.gov.it/export/sites/sitodt/modules/documenti_it/regolamentazione_bancaria_finanziaria/consu ltazioni_pubbliche/Schema_di_Regolamento_di_disciplina_dei_requisiti_patrimoniali_e_di_indipendenza_delle societx_di_cons.pdf). The most important rule in the latter is in Art. 3, that closely resembles the rule for CF; 
not have any relationship whatsoever with product providers or intermediaries, if this relationship may affect their independence (it seems a rather recursive definition), and - more importantly and clearly - they are prevented from receiving any form of 'benefit' (in the wording for CF) or 'remuneration' (as concerns SCF), from any entity other than their client. To summarize, under Italian law, what makes CF and SCF independent is essentially that they must be paid on a fee basis ${ }^{43}$, while commission is the form of remuneration of 'promotori finanziari'. We are therefore faced with a difference with the UK law: as we have seen, until the end of 2012 it is still possible for IFAs to be paid by commission, even though they must offer the fee-basis option, and their independence derives from the fact that they are untied to any particular product provider, or in other words advise on the whole market.

After 2012, commission remuneration from product providers will not be any longer possible, but not just for IFAs: in fact, all financial advisers will have to set their own adviser charge, regardless of their being independent or restricted (unlike in Italy, where this prohibition is applied only to CF and SCF, and not to promotori finanziari). As a consequence, what will distinguish IFAs will be that they advise on the basis of «a comprehensive and fair analysis» of the whole «relevant market» (again, unlike in Italy, where there is no "whole of the market requirement").

When considering the possible benefits of financial advisers that we define as independent, like we are about to do in the next paragraph, it should not be overlooked that the substantive notion we are referring to may vary in different countries, even though the designation may be very similar; therefore, the advantages of independence will not be exactly the same across the board, if the notion of independence itself is not everywhere the same. With this caveat in mind, let us move to assess such advantages.

Articles 5, 6, and 7 also add some independence requirements for partners, managers, and consultants on behalf of the company.

43 One of the main professional associations of CF actually has the (English) name of National Association of Fee Only Planners (NAFOP). 


\section{Benefits (and some limits) of independent financial advice}

As is very well known and documented ${ }^{44}$, information asymmetry lies at the heart of financial markets, and is one of the main rationales for regulating them. On its turn, information asymmetry typically leads to the problem of principal and agent. Particularly as far as the topic of financial advice is concerned, the obvious issue is that the consumer/investor lacks the knowledge to make informed judgments on the financial products available, and therefore he either guesses on his own, thus in many cases not making something much different than a pure gamble, or - more realistically - he relies on some expert's advice ${ }^{45}$. Here is where the problems arise.

Indeed, there is a broad policy interest, on which it seems hard to disagree, in making the goals and benefits of the adviser coincide with that of his client. The question is though: how do we make this happen? Generally speaking, it would seem that an adviser that is independent is more likely to fulfil this goal than one that also pursues other interests, on anyway is not free to provide the best possible advice, depending for his reward on some product provider that not necessarily wants the customer to be offered the best option (namely, that will tend to prefer the customer to be offered preferably its product, be it the best option or not). Let us dig deeper into this per se straightforward statement.

Whether we define independent advice as the one that is given on the whole market (like in the UK), or as the one that is paid directly by the client, without the adviser receiving any commission from the product providers (like in Italy), the problem with non-independent advice is that there is the potential for a serious conflict of interests between adviser and customer $^{46}$ : if the adviser only has a limited range of products to recommend to investors, or if his reward is made of commissions, the level of which is set by the product providers, there is the risk that his advice is not suitable for the customer. Indeed, he may not be able to find a suitable product among the ones he advises on, or have the incentive to recommend the

\footnotetext{
44 See, among very many, D. Llewellyn, The Economic Rationale for Financial Regulation (FSA Occasional Paper, April 1999).

45 More deeply on this issue, see FSA, Review of the Prudential Rules for Personal Investment Firms (DP 07/4, July 2007), Chapter 3, Market failure analysis, pp. 13-7.

46 See for example J.R. Boatright, 'Conflicts of Interest in Financial Services', (2000) 105 (2) Business and Society Review : 201-19 (particularly pp. 210-1); from an economic perspective, M. Krausz, J. Paroush, 'Financial advising in the presence of conflict of interests', (2002) 54 Journal of Economics and Business : 55-71; see also many references in Moloney, How to Protect Investors, pp. 244-78; finally, significant insight was brought about by Charles River Associates Ltd, 'Polarisation: research into the effect of commission based remuneration on advice' (Report for the FSA, January 2002), especially pp. 1-9.
} 
products that afford him the highest commissions, not the ones that are in the 'best interests' ${ }^{\prime 47}$ of the client.

This potential conflict of interest is a typical candidate for regulation, as was manifest in the British example. We described above the evolution of regulation of IFAs in the UK, but in parallel there has been a series of developments also in the rules concerning non-independent financial advisers. FSA has thus revised over time the requirements it imposed on them, especially adjusting its Conduct of Business rules ${ }^{48}$ in the attempt to neutralize the risks of conflict of interest we have briefly outlined here. Indeed, as acknowledged by the FSA itself, «the market failures are not being fully corrected by the current rules» 49 .

The latest round of rules brought about by the RDR, particularly the ones on remuneration of financial advisers analysed above, seem to be a very significant step in the right direction, as we will explain in $\S 5$. However, the point is that Conduct of Business rules will arguably never be able to fully neutralize conflicts of interests between non-independent advisers and investors, and this is because it is implicit in their being restricted to a limited range of products, or paid by commission, to have at least some incentive to pursue interests different than the ones of the customer, and no COB rule can do away with that.

The mirror image of this is that a healthy financial market cannot exist without a significant presence of "truly" independent financial advisers (what is the minimum requirement to consider them "truly" independent will be investigated in $\S 5$ ). Indeed, even with a minority portion of the market for financial advice, independent advisers are a viable alternative for investors to turn to for financial advice, and therefore are able to exercise a very significant source of competitive constraint on their non-independent counterparts: the latter will be aware that, if they do not take steps to defuse, at least to a certain extent, the possible harms to

47 Quoting the phrase used by Art. 19 of MiFID, and Art. 26 and 45 of MiFID's Level 2 Implementing Directive.

48 Conduct of Business rules are indeed more suited to address the market failures we are considering, as pointed out in FSA, Review of the Prudential Rules for Personal Investment Firms (DP 07/4, July 2007), Chapter 4, Can prudential rules reduce the frequency of mis-selling?. However, as showed by the very existence of this DP, followed by Feedback Statement 08/2 (April 2008) and Consultation Paper 08/20 (November 2008), the FSA also provided for some prudential regulation requirements to complement the RDR proposals (typically, capital adequacy and professional indemnity insurance requirements); the latter are not particularly relevant to the purposes of the present work, so they will not be dealt with here.

49 FSA, Review of the Prudential Rules for Personal Investment Firms (CP 08/20, November 2008), p. 5. See also FSA, Notification to the European Commission, supra note 27: «Overall, this approach has not been successful in the way that we had hoped at reducing the focus of competition in the industry on the amounts of commission paid to investment intermediaries by product providers» (p. 7); «while in the past we had hoped to rely upon consumer awareness of the commissions being paid to their advisers to mitigate the risk of remuneration bias affecting recommendations made, our understanding of consumer behaviour and financial capability confirms that UK consumers currently struggle to understand how their adviser is paid» (p. 12). 
consumers arising from the conflicts of interests they have, consumers may switch to independent advisers.

To be sure, given these premises, one could wonder if it would not be desirable to go even further, and essentially make all advisers become independent, or in other words only allow financial advice that can properly be described as independent. However, as acknowledged by the FSA, independent advice cannot be seen as a sort of passe-partout solution, that is the most suitable always and in every circumstance: "we emphasise that we do not view independent advice as necessarily the best service for every consumer» ${ }^{50}$.

The FSA does not explain the reasons for this statement, but we can find at least two very relevant ones: on the one hand, preventing product providers from selling their own products through appointed agents would manifestly be an extremely overinclusive measure, most probably contrary to EU law and freedom of enterprise. But there is also the less obvious fact that independent advisers do not seem to be perfectly suitable to everyone's needs: in particular, they works best if the assets they advise on are above a certain threshold (because below it, the margins may not be high enough, there may not be room for an effective independent administration, and so on $)^{51}$. As a consequence, depriving investors with a limited amount of money of the chance to consult tied advisers would end up meaning cutting off the possibility for them to rely on decent financial advice at all: it follows that such a radical solution cannot be accepted.

A possible compromise option would rather be to forbid «providers to play any role in remuneration», and «the simplest way to achieve this could be to ban all forms of commission, so that clients always pay their advisers' fees themselves» ${ }^{52}$ : this avenue was actually explored by the FSA, but eventually it was ruled out. Indeed, even though the FSA does not give details here either, it hints at the following problems: «tax advantages [...] [may] accrue to a customer when payments for advice are made through the product», «independent adviser firms may want to offer services that involve charging clients a percentage of their investments at given intervals, in return for periodic advice, aligning their rewards with their clients' investment returns», and «a wider ban on commission may be inconsistent with

50 FSA, FS 08/6, p. 45.

51 This seems to be confirmed by some figures provided by the UK Association of IFAs (AIFA): according to them, currently «in the UK, IFAs account for over $70 \%$ of all financial services transactions in the UK (measured by value)», yet this corresponds to only «16\% of the UK population [which is] regularly using an adviser» (AIFA, Contribution to European Commission, Directorate General Internal Market and Services Consultation on the review of the Markets in Financial Instruments Directive (MiFID) (January 2011), p. 1). This tells us that, at least for the moment, IFAs seem to represent an option preferably for wealthy individuals.

52 FSA, FS 08/6, respectively p. 6 and p. 33. 
MiFID» ${ }^{53}$, because it would probably run afoul of the freedom of establishment of foreign firms ${ }^{54}$.

One last point to make is that the existence of independent financial advisers, and the constraint they pose on tied or restricted ones, can also be seen as a promising alternative to extensive COB regulation: at least ideally or in presence of certain conditions, competitive constraints from independent advisers seem to be able to provide non-independent ones enough incentives to act in the interest of the customers, thus achieving potentially the same goals that COB rules aim at, and taking care of the problem of conflicts of interests.

As we just said, though, in order for this outcome to be realistic, there seems to be the need for certain prerequisites to be in place. The most important would be the following: the average consumer needs to be financially educated enough to know the existence of independent advisers and be aware of what distinguishes them from tied or restricted ones; in a similar vein, consumers should be able to tell how much they are paying for advice, and not make the mistake of considering it free; consumers must not be locked-in, namely there must not be barriers that discourage their switching from restricted to independent financial advisers; there must not be other obstacles to the independent advisers' ordinary carrying on of their job.

There are several strategies to achieve these preconditions. Among these, we are interested in the role that a properly devised regulation could play: indeed many will argue that it could be a very meaningful one, if not that regulation should have the lion's share in pursuing these objectives. Certainly, even if it is possible to disagree on whether or to what extent regulation should positively intervene to remove obstacles and barriers, it seems a highly desirable policy objective that at least regulation does not itself erect barriers of any sort that make it harder for independent financial advisers to effectively constrain tied ones. In the remaining paragraphs, we will first give an overview of the cornerstones of regulation of financial advice in Europe (still contrasting in particular the UK with Italy), paying particular attention to the issues more relevant to achieve the goals just mentioned; then we will inquire into to what extent the existing regulation fulfils thes goals; and finally, we will look at what improvements could be made.

53 Ibidem, p. 33.

54 The FSA, Retail Distribution Review - Interim Report (April 2008), p. 18, also explained that «outright caps on commission rates or fixed tariffs would clearly create concerns in regard to competition». 


\section{Regulation of financial advice in the EU, the UK and Italy: the essentials}

\subsection{EU law}

The first significant piece of legislation in the European Community, providing for some minimum harmonization and mutual recognition in retail financial markets, was the Investment Service Directive ${ }^{55}$ (ISD). However, the ISD included advice in the secondary activities, designated as 'non-core services' (Annex, Section C): as a consequence, an investment firm could not be granted authorization to business if it only provided investment advice, given that Article 3(1) stipulated that «authorization within the meaning of this Directive may in no case be granted for services covered only by Section C of the Annex»: investment advice was therefore unregulated (and also undefined) ${ }^{56}$.

The turning point came more recently, with MiFID. Recital (3) clearly explains that investment advice shall be included in investment services requiring authorisation, «due to the increasing dependence of investors on personal recommendations». Annex I, Section A, No. (5) then carries into practice this indication, including investment advice in the list of investment services and activities (therefore not considering it any longer one of the secondlevel activities, renamed by Section B "ancillary services") ${ }^{57}$.

In Title II, then, MiFID provides the key framework for the regulation of financial advice across the EU; firms that are subject to these rules are entitled to avail themselves of the authorisation received in one Member State in order to operate in any other Member State (it is the so called passport system, set out by Articles 31 and 32).

However, MiFID also contains, in Article 3, a fundamental 'optional exemption', according to which «Member States may choose not to apply this Directive to any persons for which they are the home Member State that: - are not allowed to hold clients' funds or securities and which for that reason are not allowed at any time to place themselves in debit with their clients, and - are not allowed to provide any investment service except the reception and transmission of orders in transferable securities and units in collective investment undertakings and the provision of investment advice in relation to such financial instruments, and — in the course of providing that service, are allowed to transmit orders only to» a list of authorised investment firms and credit institutions.

55 Council Directive 93/22/EEC of 10 May 1993 on investment services in the securities field, OJ 1993 No. L141/27.

56 A. Sciarrone Alibrandi, 'La "consulenza in materia di investimenti": profili di novità della fattispecie', in L. Frediani and V. Santoro (Eds.), L'attuazione della direttiva MiFID (Milano, 2009), p. 74.

57 For the definition of "investment advice" in MiFID, see $\S 2.1$. 
This exception was negotiated by the $\mathrm{UK}^{58}$, and indeed the UK has made use of this opt out clause $^{59}$, therefore a vast amount of financial advisers in that country are so called "nonMiFID firms", subject to the FSA regime instead of the harmonized EU one ${ }^{60}$; Italy has done the same in the above-mentioned Articles 18-bis and 18-ter of Legislative Decree 24 February 1998, No 58.

As a consequence, MiFID regulation in the field of advice only has room for residual application, when national law does not apply. However, it remains important to consider its main points: first, because there are still several firms that chose to opt in and be non-exempt, principally to benefit from the passport system ${ }^{61}$; second, because the exception is only valid in relation to persons whose home Member State has applied it, therefore MiFID is still relevant for firms from countries that did not apply it; and third, because, in any case, MiFID is a benchmark for national law, that in many cases provides for the same requirements. Let us then consider MiFID rules relevant for financial advisers in general, with particular attention to the ones most relevant to independent advisers.

The first point to make is that MiFID does not dictate rules specifically for independent financial advisers: in fact, it «merge[s] independent investment advice and product distribution/advised sales» ${ }^{62}$, stipulating rules that apply to both. As we shall see, national regulations follow quite a different path.

In any case, MiFID contains both prudential and conduct of business rules: as for the former, Article 5 stipulates that the professional performance of all investment services or activities shall be subject to prior authorisation by Member States; Art. 67 deals instead with the initial capital requirement, and introduces a lower threshold than the general one of Article 12, for «firms which are only authorised to provide the service of investment advice and/or receive and transmit orders from investors without in both cases holding money or securities belonging to their clients and which for that reason may not at any time place themselves in debit with their clients» ${ }^{63}$.

58 Moloney, How to Protect Investors, p. 206.

59 HM Treasury, 'The Financial Services and Markets Act 2000 (Markets in Financial Instruments) (Amendment) Regulations 2007' (SI 2007/763), regulations 2 and 3.

60 AIFA, Contribution to European Commission, supra note 51, p. 1.

61 Ibidem.

62 Moloney, How to Protect Investors, p. 270.

63 The rule also specifies that the initial capital requirement can be replaced by the underwriting of professional indemnity insurance, representing at least a minimum sum. 
As for the conduct of business rules, we are concerned especially by Article $19^{64}$ : $\S 1$ sets out the generic rule that «an investment firm act honestly, fairly and professionally in accordance with the best interests of its clients and comply, in particular, with the principles» outlined in the following paragraphs. Among these, $\S 2$ stipulates that «All information [...] addressed by the investment firm to clients or potential clients shall be fair, clear and not misleading»; $§ 3$ adds the disclosure obligation to provide clients with information - for that matter - on the firm, its services, its costs and associated charges, «so that they are reasonably able to understand the nature and risks of the investment service [...] that is being offered and, consequently, to take investment decisions on an informed basis»; but most of all, $\S 4$ specifically deals with the provision of investment advice: «when providing investment advice or portfolio management the investment firm shall obtain the necessary information regarding the client's or potential client's knowledge and experience in the investment field relevant to the specific type of product or service, his financial situation and his investment objectives so as to enable the firm to recommend to the client or potential client the investment services and financial instruments that are suitable for him».

As envisaged by the so called Lamfalussy Report ${ }^{65}$, MiFID was then followed by a Level 2 Directive, the already mentioned MiFID's Level 2 Implementing Directive. It is worth briefly reviewing the main contents also of this document: first of all, recital 39 stipulates that «the receipt by an investment firm of a commission in connection with investment advice or general recommendations, in circumstances where the advice or recommendations are not biased as a result of the receipt of commission, should be considered as designed to enhance the quality of the investment advice to the client»; Art. 4 contains the so called 'gold plating' rule, that significantly limits the ability of Member States to impose additional requirements to the ones provided for by the Level 2 Directive itself; then follow the requirements that firms have to meet regarding their general organisation (Art. 5), and the «policies and procedures» to adopt to comply with MiFID (Art. 6) and implement an adequate risk management (Art. 7); Articles 16 to 19 contain the rules meant to safeguard clients' assets, while Articles 21 to 25 deal with the conflicts of interests between firm and client and how to prevent such conflicts from harming the latter.

Chapter III is instead concerned with the conduct of business rules, and contains some important provisions on inducements (Art. 26), on the information that must be disclosed to

64 Article 18 requires firms to take measures in order to avoid conflicts of interests with their clients (but independent advisers should be by definition immune from this risk).

65 Final Report of the Committee of Wise Men on the Regulation of European Securities Markets (2001). 
clients (Articles 27-34), on how firms must assess the suitability and appropriateness of the transaction they recommend (Articles 35-37), on the obligations to report to clients (Articles 40-43), on the criteria to follow in order to comply with the duty of best execution (Art. 44), on the duty to act in the best interest of clients (Art. 45), on how to handle clients' orders (Articles 47-49), and on record-keeping (Art. 51).

As anticipated, all these rules are only applicable to the firms that do not enjoy the status of "exempt firms" (pursuant to MiFID Article 3), which are subject instead to national rules. Exempt "Article 3" firms, though, are the majority, thus national rules are the most frequently applied in the field of financial advice. We shall now briefly describe the UK and the Italian framework.

\subsection{UK law}

A key feature of the UK regulation is the already mentioned discipline on remuneration: in $\S$ 2.2, we outlined the normative evolution that the UK has experienced between 1988 and the most recent reforms, set to come into force ion the last day of 2012. With these new rules, all advisers will be required to set an adviser charging, and will be remunerated in this way, not being allowed to receive commissions offered by the product providers ${ }^{66}$. The rationale is to encourage the development of independent advice, in a way moving towards making all advisers become "independent", and clearly distinguishing them from «all other regulated service[s, which] would be classed as non-advised sales» ${ }^{67}$.

Besides this rule on remuneration, and the already mentioned requirement to advise on the whole market, the other «key characteristi[c] for a truly independent sector» ${ }^{68}$ is the set of professional standards required of (all) advisers, also increased by the Retail Distribution Review with the aim that financial advice be «seen as a profession on a par with other professions» ${ }^{69}$. It is not important for our purposes to dwell too long on the details: suffice it to say that professional standard rules have three strands, namely rules «on ethical behaviour, continuing professional development (CPD) and qualifications» ${ }^{70}$. All three were partly

66 In parallel, the FSA imposed a symmetrical prohibition on product providers, outlawing their offer of any payment or benefit to advisers for recommending their products (COBS 6.1B.5R).

67 FSA, FS 08/6 p. 16.

68 Ibidem.

69 FSA, CP 09/18, Distribution of retail investments: Delivering the RDR (June 2009), p. 40.

70 FSA, CP 10/14, Delivering the RDR: Professionalism, including its applicability to pure protection advice, with feedback to CP09/18 and CP09/31 (June 2010), p. 7 
overhauled by the FSA within the context of $\mathrm{RDR}^{71}$. The regulatory choice has been to keep applying the same rules for all advisers, i.e. independent and restricted ones. This fits well with the recent move towards raising the standards for non-independent advice, and bring them closer to the ones for independent advice.

Such trend is also confirmed by two other recent innovations, that affect the job and the potential spread of independent financial advisers, and that complete the reforms already outlined. The first one is the widening of the range of products to which the independence requirements apply: as we anticipated in $\S 2.2$, pursuant to COBS 6.2.15R, the current requirements only relate to packaged products, namely «units in regulated collective investment schemes (which include units in UCITS and certain non-UCITS retail schemes), shares in investment trusts (when sold through a dedicated service), life assurance policies with an investment component and certain types of pension product» ${ }^{72}$.

Inter alia, the new rules introduced with the RDR make the following changes: they entirely delete COBS 6.2, they relate the notion of independence to 'retail investment products' ${ }^{73}$, instead of packaged products, and they insert in the Handbook Glossary a definition of this new notion of 'retail investment product[s]', that, «in addition to packaged products, includ[e] unregulated collective investment schemes, all investments in investment trusts (not just those in investment trust savings schemes), structured investment products, and other investments which offer exposure to underlying financial assets, but in a packaged form which modifies that exposure» ${ }^{74}$.

The consequence is that «firms that provide independent investment advice to retail clients will be expected to consider more than just packaged products for their clients» ${ }^{75}$, therefore posing IFAs the challenge to «ensure they have sufficient knowledge of all of the types of products which could give a suitable outcome for their clients»: this matches the enhanced professional standards imposed to all financial advisers, outlined just above.

The other regulatory innovation concerns all financial advisers, but was introduced specifically to help the development of independent advice: it concerns the way advice services are described to the clients. The new rules brought about by the Retail Distribution Review (Adviser Charging) Instrument 2010, in force since 31 December 2012, will require

71 See in particular FSA, PS 10/18, Competence and ethics. Feedback to CP10/12 and final rules (December 2010), and PS 11/01, Distribution of retail investments: Delivering the RDR - professionalism. Feedback to CP10/14 and CP10/22 and final rules (January 2011).

72 As explained by the FSA in its 2008 Interim Report, p. 15, note 17, summarizing the Handbook Glossary definition.

73 COBS 6.2A.3R.

74 FSA, CP 09/18, p. 11.

75 Ibidem. 
all firms to disclose in writing to their retail clients, «in good time before the provision of» advice, whether such advice will be independent or restricted ${ }^{76}$ (specifically using these words $^{77}$ ). On top of that, a firm that provides restricted advice and «engages in spoken interaction with the retail client» will be required to «disclose orally in good time before the provision of its services in respect of a personal recommendation that it provides restricted advice and the nature of that restriction» ${ }^{78}$.

These rules, even though falling short of requiring firms «to specifically inform a client receiving restricted advice that independent advice is also available» ${ }^{79}$, were designed by the FSA with the clear goal of making consumers aware of the type of advice that they are being offered, so that they can make an informed choice and choose to address themselves to independent advisers, if they do not deem restricted advice suitable for their needs ${ }^{80}$.

\subsection{Italian law}

Finally, moving to describe Italian law, we also reviewed in $\S 2.3$ the basic provisions on the definition of financial advisers and on their remuneration. As we saw, Italian regulation of independent advice is very recent; to be sure, it is not complete yet. However, it is interesting to point out that, since the beginning, Italy has equated the notion of independence with that of fee-only remuneration, while the prohibition on IFAs to receive commissions was introduced in the UK only with the most recent rules, and will actually come into force only at the end of 2012.

A characteristic feature of Italian legislation is the provision of two different entities: CF, namely the natural persons, and SCF, the legal persons: they are regulated separately, even though the rules are very similar to each other, so we will consider them together. In order to operate, both CF and SCF must be registered in the official roll of financial advisers. This roll is provided for by Art. 18-bis and 18-ter of Legislative Decree No 58 of 1998, but its entry

\section{COBS 6.2A.5R.}

77 COBS 6.2A.6R.

78 COBS 6.2A.9R.

79 FSA, PS 10/6, p. 15. Ibidem, the FSA explains that this «is likely to be clear from the disclosure that is given to the client», and reminds that «it is also important to note that, where restricted advice is given, a firm is still required to meet the suitability requirements».

80 The new rules made redundant the previous "requirement to disclose hard commission", as far as personal recommendations are concerned: this requirement is still provided for by COBS.6.3R, whose $\S$ (1)a) stipulates that «(1) If a firm sells, personally recommends or arranges the sale of a packaged product to a retail client, and subsequently if the retail client requests it, the firm must disclose to the client in cash terms: a) any commission receivable by the firm or any of its associates in connection with the transaction [...]». As has been repeated, since 2013 no adviser will be allowed to receive any commission, therefore the Retail Distribution Review (Adviser Charging) Instrument 2010 has coherently deleted the words «personally recommends» in the rule just quoted (also this change will be effective starting from the end of 2012). 
into force was delayed many times, the latest until 31 December $2011^{81}$. Very recently, Art. 29, § 1-bis of Decree-Law 6 July 2011, No 98 (converted in Law 15 July 2011, No 111) stipulated that all the professional rolls and registers, save some exempted ones, will be abolished after an eight-months' time, and the relevant activities will be free from authorisation. Financial advice should not be included in the exempted categories, therefore it is currently not clear whether the roll will ever enter into force.

In any case, for CF and for the natural persons that act on behalf of SCF, admission to this roll would be subordinated to an exam (that would not seem to be envisioned as particularly challenging); also, in order to be admitted, CF and SCF would need to underwrite professional liability insurance.

But besides that, there are two other essential characteristics of the Italian law of financial advice. The first one is in the above-mentioned Art. 18-bis and 18-ter, and is connected to the optional exemption in Article 3 of MiFID: according to these two Articles, CF and SCF respectively are authorised to provide financial advice only on condition that they do not hold clients' money or financial instruments. Pursuant to these provisions, all Italian CF and SCF are automatically Article 3 non-MiFID firms, and therefore are subject to national law (and cannot benefit from the passport system); more importantly, no CF or SCF can hold client's money or securities, which is a significant difference from IFAs, that can still be independent even if they hold clients' financial instruments (they will simply not be Article 3 exempt firms, and will therefore be subject to MiFID).

The other very important rule to mention is on the same page: the regulation implementing Articles 18-bis and 18-ter ${ }^{82}$ prohibited CF and SCF from to accepting any power of attorney from their clients to pass orders on their behalf, or dispose of their money or securities ${ }^{83}$. Also this provision marks a significant difference from IFAs, that in their business authorisation can be allowed to pass orders on behalf of their clients, not being subject to such an outright ban.

To conclude, we shall still mention briefly some other significant rules brought about by the same regulation by CONSOB: the same Art. 12 on the conduct of business rules prescribes that CF and SCF must, among other things: behave with diligence, fairness and transparency, in particular providing clients or potential clients with the necessary information for them to understand the nature and features of the advice service and of the recommended product,

81 By Decree of the President of the Council of Ministers 25 March 2011.

82 Adopted by CONSOB on 12 January 2010, with Deliberation No. 17130.

83 Art. 12, § 3; Art. 27 provides that CF and SCF that are found in violation of this rule shall be struck off the roll. 
thus making informed investment decisions ${ }^{84}$; acquire from clients or potential clients the necessary information to classify them and be able to recommend them products that fit their needs; act in the clients' interest and inform them of possible conflicts of interest in which they find themselves that may harm their clients' interests.

Also, CF and SCF must: take care of their professional update (Art. 14); obtain the necessary information from the clients in order to be able to classify them as retail or professional clients, otherwise they must refrain from providing advice (Art. 17); provide clients with detailed information on the products recommended, including its explicit and implicit costs and how much overall they will have to pay for such products (Art. 18) ${ }^{85}$; make sure the recommended operation fits the clients' needs (Art. 19); provide a profit and loss report (Art. 20); adopt adequate procedures to meet their requirements and be able to reconstruct their behaviour in the provision of advice (Art. 24); take adequate measures to identify and defuse conflicts of interests, even keeping a register of the situations of potential conflict of interest (Art. 25); keep track of the advice given and all the recommendations provided (Art. 26).

Finally, Art. 13 stipulates that the provision of financial advice by CF and SCF is incompatible with, among others, the job of 'promotore finanziario' ('financial promoter'), that as we saw is roughly the equivalent of restricted advisers. This is another significant difference with the UK discipline, where - even after the latest overhaul - the same firm can be at the same time independent and restricted, according to the clients or the services offered: this would never be possible in Italy, where independence is not a feature of the advice provided but of the firm itself, which cannot therefore be one thing and its opposite.

And speaking of 'promotori finanziari', it is still worth mentioning that they are also subject to a duty to provide some information to the clients or potential clients when they meet them for the first time ${ }^{86}$, but this information falls short of making it particularly clear to the clients that they are dealing with a tied adviser: as we saw, in the UK the RDR tried instead to get rid of any potential confusion, by mandating disclosure of the nature of the advice provided, specifically imposing the use of the words restricted or independent.

84 This duty is repeated by Art. 15, which adds that the clients must also be informed of the remuneration due to the adviser, the other activities the adviser carries on, the type of clients the adviser addresses to, and other information, including on the content of the contract; the mandatory contents of the contract are then listed in Art. 16.

85 Art. 21 gives further details on the requisites of such information, and Art. 22 and Art. 23 on how to fulfil the duty to provide them.

86 Art. 108 of CONSOB regulation 29 October 2007, adopted with Deliberation No 16190. 


\section{Is financial advice adequately regulated? An assessment of the state of the art}

After reviewing the architecture of investment advice regulation, in the EU and in the two countries we have selected, it is now the time to try to assess its merits and shortcomings, the way it has come to be with the more recent reforms; in the final paragraph, we will evaluate the proposals for further overhauls that are currently under consideration, and review other possible improvements that could be devised.

We will start from where we started our analysis, namely from the question of definition. It is then time to ask: do the laws considered define independent financial advisers that are truly independent? From a normative perspective, we argue that the bottom-line to consider a financial advisor independent is connected to its remuneration: if the only money they make comes from their clients, and they do not receive commissions from product providers, it seems reasonable to exclude the risk of conflicts of interests, and therefore appropriate to deem them independent.

The corollary is that fee-only-based remuneration seems then the necessary and sufficient condition for independence: it is necessary because otherwise product providers are able to influence advisers, by offering them handsome commissions if they recommend their products; but it also seems to be sufficient, because once the only relationship is between advisers and clients, with product providers playing no role, this seems enough to guarantee that the incentive for advisers is to act in their clients' best interest. Whether they actually provide good advice or not, it will depend on how good they are, but this should arguably no longer be a concern for regulators: the task should be left to a well-functioning market of letting emerge which are the good and the bad advisers. So how do EU, UK and Italian law respectively perform against this background?

As we saw, EU law does not provide for criteria to define when financial advice can properly be considered independent. In fact, it arguably should: it is acceptable and probably even to be welcomed that different Member States have different rules in place, but it would be preferable if such rules were grafted on to a uniform definition, so that the object of regulation is everywhere the same, comparisons and regulatory competition are made more practicable, and most importantly, the creation of a single market also for financial advice is facilitated. Until no common core exists at the definitional level, it will be much harder for such a scenario to materialize.

Anyway, moving on to the Italian case, the assessment of its definition of independent financial advisers in light of the criteria we have outlined seems quite easy: by forbidding 
commissions outright, the legislature itself made sure that CF and SCF are free from conflicts of interests with their clients.

As for the UK, as we saw the more recent reforms have come to a very similar outcome, and it seems therefore that, starting from 2013, there will not be any more doubt of the genuine independence of IFAs: this seemed much more questionable certainly under the rules in force until depolarisation, but also under the ones in force until the end of 2012, because fee remuneration was just an option, and not even very popular ${ }^{87}$. It is true that there have already been quite a few major overhauls in the field, and if one reads the FSA papers accompanying them, he realizes that each time the FSA hoped that the reform of the time would be quite decisive in offering clarity to consumers and letting the industry of independent advice thrive, but then after a while they honestly admitted that not everything was working according to the expectations.

However, the reforms set to enter into force at the end of 2012 seem to have finally centred the crucial point, i.e. the issue of remuneration, and dealt with it in the proper way: from now on, all IFAs will be called independent with due cause. This may have the effect of inducing several advisers to go restricted ${ }^{88}$, in order to be free from these restrictions, but it seems not too high a price to pay for the benefit of clarity for consumers.

In any case, there are still at least two remarkable divergences between the two countries we have analysed: the first is that, as we saw in $§ 2.1$, the UK definition also includes the "whole of the market requirement", while we deem it better to just focus on the arguably only decisive element (the fee-only remuneration). The second, more important aspect was just pointed out at the end of last paragraph: it is the fact that, in the UK, it is the advice - rather than the firm - to be characterised as independent or not, while in Italy it is the firm itself providing advice $^{89}$. The consequence is that, in the UK the same firm can be considered as providing independent advice or not, according to the circumstances, and even a provider selling its own products can be deemed to act independently, provided it meets the proper requirements ${ }^{90}$. The fact that in Italy this cannot happen seems to be a point in favour of its discipline, because it is able to provide far more clarity to consumers, which is arguably never enough in this field.

87 FSA, FS 08/6, p. 32: «At present, the most common method by which independent adviser firms are paid is to receive commission from product providers, in return for arranging sales of their products».

88 This concern was actually expressed in the consultations led by the FSA, as explained in FSA, PS 10/6, p. 12. 89 The draft regulation for SCF (supra, note 42) even stipulates that SCF must include the designation of "SCF" within their company name (Article 2(2)).

90 FSA, CP 09/18, p. 12. 
Probably, it would have been even more appreciable if the Italian legislator had made a bigger effort to choose more clear designations for CF and SCF, that included the crucial word 'independent'. From this point of view, the thorough market research conducted by the FSA in order to find out which label would be the best counterpart to independent financial advisers (ended with the choice of restricted) ${ }^{91}$ is something that would have certainly helped in the Italian context as well, where a very large number of consumers seem far from appreciating the difference between independent financial advisers and "financial promoters", and the relevant implications.

Instead where the UK regulation appears to be a cut above is in two, very relevant aspects. The first one regards the disclosure obligations that - as we saw - have long been introduced, and have been confirmed with the most recent overhaul. So far, they have not been entirely satisfactory in achieving the goal of providing consumers with the desired clarity, but combined with the rules resulting from the latest overhaul, they seem quite incisive and finally likely to let most investors learn the difference between independent and nonindependent advice, and be aware of which one they are being offered. By contrast, Italian law does not seem as effective, not imposing on the non-independent counterparts of CF and SCF, i.e. promotori finanziari, an obligation to explicitly warn potential clients of the restricted nature of the advice they are offering them.

The second aspect is that UK regulation is on the whole much more flexible than its Italian homologue, allowing IFAs to perform certain important activities, without losing their status as independent firms, unlike what happens under Italian law. In particular, the FSA rules allow IFAs both to hold clients' money, and to transmit orders to other intermediaries on behalf of their clients, while Italian law rules out both these chances. We will use the space until the end of this paragraph to dig deeper into these two interconnected aspects.

As we saw, the ability to hold clients' money is considered in Article 3 MiFID: if a firm has this power, the EU legislator deems it necessary to subject it to its own rules (as opposed to the national ones): in this case, the position of the adviser is obviously more delicate and can justify stricter supervision, therefore it is understandable that the EU wanted to keep it under its direct jurisdiction. However, at least if we accept our premise that what makes advisers independent, is that they are remunerated only by their clients, in no way can the fact that they hold clients' money affect the assessment of their independence.

91 See IFF Research Ltd., Describing advice services and adviser charging (FSA Consumer Research 78, June 2009). 
The same is true for the related prohibition, under Italian law, to receive a power of attorney to transmit orders on behalf of the clients: also in this case, it is hard to see why allowing this would undermine the advisers' independence, and in fact the UK has never considered such a ban (MiFID does not contain directions on the issue either). This rule seems likely to stake a claim on the growth of independent advice in Italy beyond a certain dimension, at least from the points of view that we now move to analyse.

With a very practical consideration, it must first of all be taken into account that, as a matter of fact, many clients are not willing, or do not simply have the time, to directly involve in the daily management of their investments: in fact, this is an important reason why they choose to rely on an adviser. If they trust their adviser enough, why prevent them from letting the adviser do the whole job for them (simply taking the due precautions to avoid that advisers can misappropriate the money), and instead force people to transmit the order themselves?

The loophole that has been worked out is that, when he wants to recommend an investment, the adviser transmits his recommendation to the intermediary that holds the client's money, the intermediary calls the client on the phone and asks him to confirm that he wants to execute the order that his adviser is recommending, and tape-records his consent to its execution. This is clearly cumbersome and it seriously risks to annoy and discourage many potential clients. Actually, in the vast majority of cases, the client will not be really aware of the details of the operation, and he will simply consent because he trusts his adviser: his consent manifested to the intermediary is nothing but formal, and the substance is that the adviser is the one who is actually recommending an investment. Making it appear that it is the client who on his own, after carefully assessing his advisers' recommendation, resolves to make a certain investment, seems just a quite hypocritical pretence.

But there are other inconveniences: in order for such a mechanism to work, there is the need for the independent adviser to find an intermediary willing to cooperate with him to make this triangulation possible, which is not easy because independent advisers are a competitor of intermediaries in the downstream market for investment advice (and therefore it seems hard to imagine that they can be forced to cooperate on competition law grounds ${ }^{92}$ ). If the current depositor of the client's money is not willing to perform such a task, the adviser needs to find one who is, and then convince his client to transfer his money there, which the client may not be happy or de facto able to $\mathrm{do}^{93}$.

92 For some remarks on the room for competition law in the area under consideration, see $\S 6$.

93 As we shall see in the last paragraph, this may be due to obstacles and resistance from the current intermediary. 
Clearly, such problems do not arise when clients are willing to directly execute the recommendations they receive from the advisers. But still, the prohibition to transmit orders on clients' behalf limits independent advisers substantially: first, because - as trivial as this remark may be - it takes significantly more time to call or email every client of yours, rather than directly transmitting the order on their behalf. This inevitably reduces the number of clients that realistically each adviser can handle, drawing a model of independent financial adviser who can only be the old-style professional working with a limited number of clients and growth perspectives. Italian regulation therefore is likely to freeze out from the outset the chance for CF - and also SCF - to achieve economies of scale that could on their turn generate efficiencies that could finally lead to lower costs of advice for consumers.

And finally, such model also cuts off many opportunities to develop a lively industry of independent advice for investments where it is crucial to execute an order as fast as possible, as soon as the proper signal is triggered, as typically in intra-day trading: again, if the adviser has to call or email each of his clients, the opportunity may be gone after the first phone call or two, and it is really hard to imagine how a business can develop in such conditions. But why undermine many chances for investors to receive independent advice for intra-day operations?

The conclusion that it would be more reasonable to draw is that the Italian legislator (for the prohibition on handling clients' money) and even more CONSOB, the sector-specific regulator (for the prohibition to receive powers of attorney), did not give enough consideration to the task of creating the conditions for the birth of the industry of independent financial advice.

One could also suppose that incumbent (non-independent) financial advisers lobbied to have such obstacles in place to the growth of some potentially relevant competitors. However, quite surprisingly indeed, not only were such requirements never opposed by the main trade associations of CF and SCF, but they themselves lobbied CONSOB for providing the punishment of radiation for independent advisers who violated the ban on the acceptance of powers of attorney ${ }^{94}$, or anyway got hold of a client's codes to transmit orders ${ }^{95}$. This

94 NAFOP, Documento di consultazione relativo al Regolamento CONSOB emanato ai sensi dell'articolo 18BIS del D.Lgs. N. 58/98 in materia di Consulenti Finanziari [Consultation on CONSOB Regulation implementing Article 18-bis of Legislative Decree No. 58/98 on CF], 30 June 2008, p. 13, available at http://www.consob.it/.

95 AssoFinance, Regolamento di attuazione dell'art. 18-bis del D. Lgs. N. 58/98 in materia di consulenti finanziari. Documento di consultazione del 5 giugno 2008 [Regulation implementing Article 18-bis of Legislative Decree No. 58/1998. Consultation paper of 5 June 2008], p. 5, available at http://www.consob.it/. 
punishment was indeed not included in a first draft of the regulation, but was then included in the final version, presumably complying specifically with the wishes of the trade associations. The reason for such a choice by the latter remains unclear to us, and the only sensible explanation we have been able to come up with is that, facing the very hard task of finding a way to let consumers know that an alternative to traditional investment advice was born, and to earn market share from scratch to the expense of very powerful and well-established incumbents, the trade associations of CF and SCF chose a down-to-earth approach, and considered that the only realistic chance they had to succeed was to market themselves as completely different than the traditional investment advisers. This meant to underline not just their independence, but also the fact that there would never be the chance that they misappropriate their clients' money, because such an event is radically cut off by the law itself.

Clearly, if one takes the short-term view, for the single independent adviser who wants to start his own business, it may seem a prohibitive task trying to build up the reputation needed to convince a minimum amount of clients to let him transmit investment orders on their behalf, and handle their money in connection to this. His reputation needs to be well-established enough for clients to entrust him with such a task, but - the point could be made - it may never be doable to establish such reputation unless he tries to convince clients that there is not even a remote risk that he will misappropriate their money, or even "touch" it without their consent. To which it can be replied that lifting these bans would obviously not mean that the clients are obliged to give away their money or to grant a power of attorney, but simply that they can, if they wish, and trust their adviser enough. Reputation is definitely hard to establish, but nonetheless it should probably not be artificially helped, because what is gained does not seem to outweigh the outlined drawbacks.

Also, from a different perspective, the use of a power of attorney and the ability to handle clients' money would arguably allow a much easier assessment of the earnings or losses determined by the advice received: in case of litigation, especially when remuneration is at least partly contingent on the returns generated by the advice, it becomes hard for the client to deny he received some advice (when the adviser is suing him to recover his fees), and vice versa for the adviser to deny he gave some advice (when things go wrong and the client is suing him for professional negligence) ${ }^{96}$.

96 It is true that Article 26 of CONSOB regulation of 12 January 2010 imposes on advisers the duty to keep detailed records of all the recommendations made, but it would seem preferable to lighten this requirement on advisers who were granted the power to operate on behalf of the clients (were this allowed): it is a bureaucratic 
Time will tell whether the pragmatic approach followed by the representatives of CF and SCF will prove to be the right (and only possible) choice to make some room for CF and SCF in such a difficult market as the one for financial advice, or if the worries put forward here will turn out to be justified, and the regulatory limits imposed on Italian independent advisers will jeopardize, in the long run, their chances to become a credible threat to traditional advisers, and not just a niche alternative for a particularly well-informed elite of consumers.

\section{Reform proposals: the ongoing MiFID review, other hypotheses of overhaul, and a bigger role for competition law}

What improvements could be imagined to the the picture described? The main existing reform proposals are currently at the EU level: in particular, within the framework of the MiFID review, the EU institutions have been considering to introduce some significant changes to the current regime of financial advice.

In particular, the Commission has proposed to «narrow the scope of the exemption [under Article 3 of MiFID] by circumscribing the powers of Member States in regulating» ${ }^{97}$ currently exempted firms, essentially mandating Member States to subject them «to requirement analogous to the MiFID ones in the following areas: a) proper authorisation process, including the assessment of fit and proper criteria [Articles 5 and 9 MiFID]; b) information to clients [Article 19(2) and (3) MiFID]; c) suitability test [Article 19(4) MiFID]; d) payments received from third parties (inducements) [Article 26 MiFID Level 2]; e) reporting to clients [Article 19(8)] and f) duty to act in the best interest of the client when transmitting orders received from clients [Article 45(7) MiFID Level 2]» ${ }^{98}$. Such proposal was opposed by trade associations of independent financial advisers in the UK and in Italy as redundant, on the basis that the respective national laws are already fully in line with MiFID conduct of business requirements and fit and proper criteria ${ }^{99}$.

More importantly, and specifically on investment advice, the Commission would bring about - among others ${ }^{100}$ - the following, crucial changes: introduce a «requirement for intermediaries to inform the investor whether they give advice on the basis of an independent

burden and it would be unnecessary if advisers operated directly, which would make it very easy to keep track of their operations.

97 European Commission, Directorate General Internal Market and Services, Review of the Markets in Financial Instruments Directive (MiFID) (8 December 2010) [EC MiFID Review], p. 52.

98 Ibidem, p. 53.

99 AIFA, Consultation Paper on MiFID Review (January 2011), pp. 1-2; NAFOP, Consultation on the review of the Markets in Financial Instruments Directive (MiFID) (2 February 2011), p. 2.

100 Chiefly consisting in further report obligations towards clients and in the granting to them of longer term assistance. 
and fair analysis» ${ }^{101}$; lay down the minimum criteria for investment advice to be presented as «based on an independent and fair analysis», i.e. assessment of «a sufficiently large number of financial instruments available on the market, notably, financial instruments of different types and from different providers», and prohibition to accept «any payments or benefits from any product providers» ${ }^{102}$.

In line with the positions expressed in the previous paragraphs, we reckon that, in general, both these requirements should be favourably welcomed: the former would contribute to provide some additional clarity to consumers; the latter would finally provide for a harmonized definition of independent advice, something that - as we explained in $\S 5$ - we believe would also positively contribute to more clarity for consumers, and create some fertile ground for the birth of a cross-border market for independent investment advice.

However, a closer analysis is necessary: similarly to the UK law that will be in force since 2013, the EC proposal would build the definition of independent advice around two elements, i.e. a ban on commissions and a whole of the market requirement. On this aspect, we would repeat our view that the requirement not to accept any benefit from product providers is the crucial one, whereas the "whole of the market" criterion is not decisive, and it would be preferable to omit it, like Italian law does.

On the other way round, as underlined by AIFA ${ }^{103}$, the EC proposal departs from the UK model, instead adhering to the one followed by the Italian legislator, on two significant points. First, the Commission is proposing to ban commissions only for independent advisers; second, the Commission would ban any payment from product providers to advisers, the UK law leaves the door open for transfers of money from the former to the latter, when this is just an alternative to the upfront payment by the client and does not undermine the advisers' independence.

To sum up, if with this caveats, the EC proposals for the MiFID review seem a promising step in the right direction, even though there are certainly some margins for improvement, and the ongoing consultation process is a very good occasion for all the stakeholders to contribute to the effort.

As for national laws, on the whole they also got to draw an appreciable regulatory setting for the growth of the industry of independent advice, particularly the UK law, now incorporating

101 EC MiFID Reveiw, p. 56: as the EC itself explains, under the current regime, «intermediaries providing investment advice are not expressly required to explain the basis on which they provide advice (e.g. the range of products they consider and assess) and more clarity is thus needed».

102 Ibidem. This requirement would be reaffirmed by symmetrical new rules on inducements.

103 AIFA, Consultation Paper or MiFID Review, pp. 5-6. 
the experience of more than two decades in regulating the phenomenon. The improvements that we would suggest are primarily the ones we have outlined in the course of the analysis, and most of all to draw the distinction between independent and non-independent firms, rather than advice, as for the UK, and to remove the outright prohibition to handle clients' money and to transmit orders on behalf of clients (on top of enhanced disclosure obligations regarding remuneration and inducements), as for Italy.

More broadly, we argue that it would not be a good idea to tighten the conduct of business rules, like envisioned by the Commission in the MiFID review, as we believe a healthy market for independent advice would already take care of delivering to consumers the proper amount of information, of reducing the conflicts of interests and of rewarding the firms that operate in the best interest of the clients, driving out of the market those that have unsatisfactory performances, thus making it at least to a certain extent unnecessary to have in place too strict a regulatory framework.

A similar argument could then be applied to the broader market for financial advice, and possibly reduce the need for tight regulation also for non-independent advisers: indeed, again if the premise of the existence of a healthy (truly) independent advice industry is realized, the competitive constraints it would be able to exercise on non independent advisers would arguably be strong enough to achieve the consumer welfare goals that regulatory requirements - sometimes quite burdensome and costly to comply with - aim at attaining.

It is therefore clear that everything depends on whether the premise is fulfilled, i.e. on whether a lively industry of independent (namely fee-only based) advice exists or not. It seems that several elements could contribute to meet this goal, and certainly, as we have tried to show throughout all this work, some properly designed disclosure obligations would help, that let consumers understand that there is no such thing as free advice and be aware of the conflicts of interests of non-independent intermediaries, deciding accordingly whom to entrust with the task of giving them financial advice.

But probably - and it is the last point we would like to make - some carefully drafted lighttouch regulation would not be enough, and it would likely need to be coupled with the tools from a different branch of law, namely competition law. Indeed, at least according to what we have learned in some informal conversations with (Italian) independent financial advisers, the main obstacles to the development of their profession are not of a regulatory source (however important such obstacles may be), but rather lie in the behaviour of traditional intermediaries. It is obviously fully legitimate that incumbent (non-independent) advisers fight not to lose market share, but the problem is that frequently they allegedly try to divert clients away from 
independent advisers in unacceptable ways. Thus, they would often scare consumers with an imaginary risk of seeing their adviser fade away with their money; or - more seriously - they would try to prevent them from switching to independent advice, typically by charging high switching costs, or by exploiting their vertically integrated nature (for examples, there are reportedly cases of very burdensome procedures established for clients who want to open a trading account and then rely on independent advice for their investments, rather than on the same intermediary's advice; or even of threats to entrepreneurs who intend to start relying on independent advice for their personal investments, of withdrawing the line of credit for their business).

Such actions by traditional intermediaries to thwart the growth of independent advice could strike a fatal blow to it, but it is hard to imagine how regulation could effectively counteract these efforts to nip independent advice in the bud. Competition law should then arguably come into play, by punishing behaviours, such as the ones exemplified, that go well beyond a commonly accepted notion of fair competition, or competition on the merits. In the classic debate on the protection of competition $\mathrm{v}$. the protection of competitors, it would be an intervention of the former type, namely the less invasive one, and it would allow professionals without conflicts of interests to exert a highly beneficial competitive constraint on traditional ones, potentially triggering a race to the top in the quality of financial advice, with all the systemic benefits of the case. 


\section{Bibliography}

- AIFA, Contribution to European Commission, Directorate General Internal Market and Services - Consultation on the review of the Markets in Financial Instruments Directive (MiFID) (January 2011)

- AssoFinance, Regolamento di attuazione dell'art. 18-bis del D. Lgs. N. 58/98 in materia di consulenti finanziari. Documento di consultazione del 5 giugno 2008 [Regulation implementing Article 18-bis of Legislative Decree No. 58/1998. Consultation paper of 5 June 2008], available at http://www.consob.it/

- J. Black, 'Forms and Paradoxes of Principles Based Regulation', (2008) 3 (4) Capital Markets Law Journal : 425-457

- J. Black, Rules and Regulators (Oxford, 1997)

- J. Black, 'The Rise, Fall and Fate of Principles Based Regulation', LSE Law, Society and Economy Working Papers 17/2010, available at http://www.lse.ac.uk/collections/law/wps/WPS2010-17_Black.pdf

- J. Black, M. Hopper and C. Band, 'Making a Success of Principles-Based Regulation', (2007) 1 (3) Law and Financial Markets Review : 191-206

- J.R. Boatright, 'Conflicts of Interest in Financial Services', (2000) 105 (2) Business and Society Review : 201-19

- Charles River Associates Ltd, 'Polarisation: research into the effect of commission based remuneration on advice' (Report for the FSA, January 2002)

- Director General of Fair Trading, The Rules on the Polarisation of Investment Advice (August 1999)

- FSA, A Review of Retail Distribution (DP 07/1, June 2007)

- FSA, Competence and ethics. Feedback to CP10/12 and final rules (PS 10/18, December 2010)

- FSA, Conduct of Business Sourcebook (MiFID, Article 4 and Other Amendments) Instrument 2007' (FSA 2007/44)

- FSA, Delivering the RDR: Professionalism, including its applicability to pure protection advice, with feedback to CP09/18 and CP09/31 (CP 10/14, June 2010)

- FSA, Depolarisation Instrument 2004 (FSA 2004/89)

- FSA, Disclosure Documents (Amendment) Instrument 2008 (FSA 2008/35)

- FSA, Distribution of retail investments: Delivering the RDR (CP 09/18, June 2009) 
- FSA, Distribution of retail investments: Delivering the RDR - feedback to CP09/18 and final rules (PS 10/6, March 2010)

- FSA, Distribution of retail investments: Delivering the $R D R$ - professionalism. Feedback to CP10/14 and CP10/22 and final rules (PS 11/01, January 2011)

- FSA, FSA guide to financial advice (August 2005)

- FSA, Fsa rules herald new era of financial advice (FSA/PN/103/2004, 29/11/2004)

- FSA, Notification and justification for amending certain requirements relating to the market for packaged products under Article 4 of Directive 2006/73/EC ("Level 2 Directive”) implementing Directive 2004/39/EC (“Level 1 Directive”) (March 2010)

- FSA, Reforming Polarisation: A menu for being open with consumers. Including feedback on CP166 (CP 04/3, February 2004)

- FSA, Reforming Polarisation: First steps (CP 80, January 2001)

- FSA, Reforming Polarisation: Implementation Feedback on CP04/3 (A menu for being open with consumers) and made text (PS 04/27, November 2004)

- FSA, Reforming Polarisation: Making the market work for consumers (CP 121, January 2002)

- FSA, Reforming Polarisation: Removing the barriers to choice. Including feedback on CP121 (CP 166, January 2003)

- FSA, Retail Distribution Review (Adviser Charging) Instrument 2010 (FSA 2010/12)

- FSA, Retail Distribution Review. Including feedback on DP07/1 and the Interim Report (FS 08/6, November 2008)

- FSA, Retail Distribution Review - Interim Report (April 2008)

- FSA, Review of the Prudential Rules for Personal Investment Firms (CP 08/20, November 2008)

- FSA, Review of the Prudential Rules for Personal Investment Firms (DP 07/4, July 2007)

- FSA, Review of the Prudential Rules for Personal Investment Firms. Feedback on DP07/4 (FS 08/2, April 2008)

- IFF Research Ltd., Describing advice services and adviser charging (FSA Consumer Research 78, June 2009)

- M. Krausz, J. Paroush, 'Financial advising in the presence of conflict of interests', (2002) 54 Journal of Economics and Business : 55-71 
- D. Llewellyn, The Economic Rationale for Financial Regulation (FSA Occasional Paper, April 1999)

- I. MacNeil, An Introduction to the Law on Financial Investment (Oxford and Portland, Oregon, 2005)

- G. McMeel, J. Virgo, Financial advice and financial products. Law and Liability, Oxford, 2001

- N. Moloney, How to Protect Investors. Lessons from the EC and the UK (Cambridge, 2010)

- NAFOP, Consultation on the review of the Markets in Financial Instruments Directive (MiFID) (2 February 2011)

- NAFOP, Documento di consultazione relativo al Regolamento CONSOB emanato ai sensi dell'articolo 18-BIS del D.Lgs. N. 58/98 in materia di Consulenti Finanziari [Consultation on CONSOB Regulation implementing Article 18-bis of Legislative Decree No. 58/98 on CF], 30 June 2008, available at http://www.consob.it/

- A. Sciarrone Alibrandi, 'La "consulenza in materia di investimenti": profili di novità della fattispecie', in L. Frediani and V. Santoro (Eds.), L'attuazione della direttiva MiFID (Milano, 2009)

- P. Smee, 'To polarise or not to polarise', (2002) 10 Journal of Financial Regulation and Compliance : $135-40$

- L. Zitiello, 'La consulenza in materia di investimenti', in L. Zitiello, La nuova disciplina dei mercati, servizi e strumenti finanziari (Torino, 2007) 